\title{
A Combined Experimental and Theoretical Study on Vibrational Spectra of 2-Phenylcyclopropan-1-Amine
}

\author{
Ganeshvar PS ${ }^{1}$, Kanagaraj $\mathrm{M}^{1 *}$, Gunasekaran $\mathrm{S}^{2}$ and Gnanasambandan $\mathrm{T}^{3}$ \\ ${ }^{1}$ Department of Physics, Karpagam University, India \\ ${ }^{2}$ St Peter's University, India
}

${ }^{3}$ Department of Physics, Pallavan College of Engineering, India

Submission: September 09, 2017; Published: October 24, 2017

*Corresponding author: Kanagaraj M, Department of Physics, Karpagam University, Eachanari, Coimbatore-641021. Tamilnadu, India, Email: kanaguphy@gmail.com

\begin{abstract}
In this work, a combined experimental and theoretical study on molecular structure, vibrational spectra and natural bond orbital (NBO) analysis of 2-phenylcyclopropan-1-amine (2PCP1A) have been reported. The optimized molecular structure, atomic charges, vibrational frequencies and natural bond orbital analysis of 2PCP1A have been studied by performing DFT/B3LYP/6-31G(d,p),6-311++G(2d,3p)and 6-31G(3df,3pd) levels of theory. The FT-IR, FT-Raman spectra were recorded in the region of $4000-400 \mathrm{~cm}^{1}$ and $3500-100 \mathrm{~cm}^{1}$ respectively. The harmonic vibrational frequencies were scaled and compared with experimental values. The observed and the calculated frequencies are found to be in good agreement. The UV-visible spectrum was also recorded and compared with the theoretical values. The calculated HOMO and LUMO energies show that charge transfer occurs within the molecule. Natural Population Analysis (NPA) was used for charge determination in the title molecule. Besides, molecular electrostatic potential (MEP), frontier molecular orbitals (FMO) analysis were investigated using theoretical calculations.
\end{abstract}

Keywords: FTIR; FT-Raman; DFT; MEP; NBO; NLO

\section{Introduction}

2-phenylcyclopropan-1-amine (2PCP1A) compound belongs to the class of organic compounds known as aralkylamines. These are alkylamines in which the alkyl group is substituted at one carbon atom by an aromatic hydrocarbyl group. This monoamine oxidase inhibitor is effective in the treatment of major depression, dysthymic disorder, and atypical depression. It also is useful in panic and phobic disorders. Phenycycloproane and its derivatives are studied by several authors. Influence of Reactant Polarity on the course of $(4+2)$ Cycloadditions was investigated by Sustmann [1]. Density Functional Theory Study of the Cycloaddition Reaction of Furan Derivatives with Masked o-Benzoquinones is carried out by Domingo [2]. Resonance Raman studies of phenylcyclopropane radical cations are studied by Godbout [3]. Weak hydrogen bridges: a systematic theoretical study on the nature and strength of C--H...F--C interactions is done by Kryspin [4]. Lysine demethylase inhibitors for myeloproliferative or lymphoproliferative diseases or disorders are studied by Mathewet [5].

In the present work, harmonic-vibrational frequencies are calculated for 2-phenylcyclopropan-1-amine (2PCP1A) using
B3LYP/6-31G(d,p), 6-311++G(2d,3p) and 6-31G(3df,3pd) methods. The calculated spectra of the compound are compared to that of experimentally observed FT-IR and FT-Raman spectra. The redistribution of electron density (ED) in various bonding and antibonding orbitals and E(2) energies have been calculated by natural bond orbital (NBO) analysis by DFT method to give clear evidence of stabilization originating from the hyper conjugation of various intramolecular interactions. The HOMO and LUMO analysis have been used to elucidate information regarding ionization potential (IP), electron affinity (EA), electronegativity (), electrophilicity index (O), hardness (O) and chemical potential () are all correlated. These are all confirming the charge transfer within the molecule and also molecular electrostatic potential (MESP) shows the various electrophilic and nucleophilic region of the title molecule.

\section{Experimental}

The compound under investigation 2PCP1Awas purchased from Aldrich chemicals, USA. The FT-IR spectrum of 2PCP1A was recorded in the region $400-4000 \mathrm{~cm}^{1}$ on IFS $66 \mathrm{~V}$ spectrophotometer using $\mathrm{KBr}$ pellet technique as shown in 
Figure 1(b). The FT-Raman spectrum of 2PCP1A has been recorded using $1064 \mathrm{~nm}$ line of $\mathrm{Nd}$ : YAG laser as excitation wavelength in the region $3500-100 \mathrm{~cm}^{1}$ on a Thermo Electron Corporation model Nexus 670 spectrophotometer equipped with FT-Raman module accessory as shown in Figure 2(a). The ultraviolet absorption spectra of 2PCP1A were examined in the range 200-400 $\mathrm{nm}$ using SHIMADZU UV-1650 PC, UV-VIS recording spectrometer using water as solvent.

\section{Computational Details}

DFT method is very much useful for the Quantum mechanical calculations of energies, geometries and vibrational wave numbers of organic chemical system. The gradient corrected density functional theory (DFT) [6] with the three-parameter hybrid functional Becke3 (B3) [7,8] for the exchange part and the Lee-Yang-Parr (LYP) correlation functional [9], calculations have been carried out in the present investigation, using 6-31G(d.p), 6-311++G(2d,3p) and 6-31G(3df,3pd) basis sets with Gaussian-03 [10] program, invoking gradient geometry optimization [11]. All the parameters were allowed to relax and all the calculations converged to an optimized geometry which corresponds to true energy minima. The optimized structural parameters of 2PCP1A were used for harmonic vibrational frequency calculations resulting in IR and Raman frequencies. The vibrational assignments of the normal modes were made on the basis of the potential energy distribution (PED) calculated by using the VEDA 4 program [12].

\section{Results and Discussion}

\section{Molecular geometry}

The first task for the computational work is to determine the optimized geometries of the title compound. The optimized molecular structure of 2PCP1A with the numbering scheme of the atoms is shown in Figure 1(a). The optimized structural parameters such as bond length and bond angles are determined by B3LYP method with $6-31 \mathrm{G}(\mathrm{d}, \mathrm{p}), 6-311++\mathrm{G}(2 \mathrm{~d}, 3 \mathrm{p})$ and $6-31 \mathrm{G}(3 \mathrm{df}, 3 \mathrm{pd})$ as basis sets. The geometry of the molecule is considered by possessing $\mathrm{C} 1$ point group symmetry. From the structural data given in Table 1, it is observed that the various benzene ring $\mathrm{CC}$ bond distances and the $\mathrm{CH}$ bond lengths of title compound are found to be almost the same at all levels of calculations.

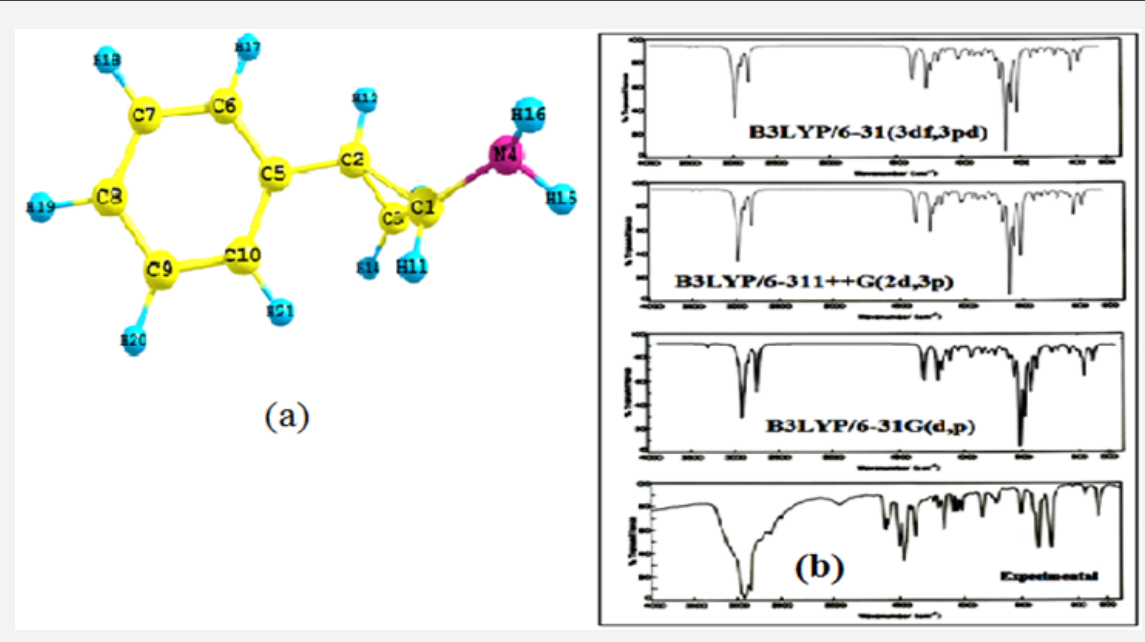

Figure 1: a) Optimized structure of 2PCP1A and b) FT-IR spectra of 2PCP1A.

Table 1: Optimized geometrical parameters with bond length and bond angle of 2PCP1A.

\begin{tabular}{|c|c|c|c|}
\hline \multirow{2}{*}{$\begin{array}{c}\text { Bond } \\
\text { length }(\AA)\end{array}$} & \multicolumn{3}{|c|}{ B3LYP } \\
\cline { 2 - 4 } & $\mathbf{6 - 3 1 G ( d , p )}$ & $\mathbf{6 - 3 1 1 + + G ( 2 d , 3 p )}$ & $\mathbf{6 - 3 1 G ( 3 d f , 3 p d )}$ \\
\hline $\mathrm{C} 1-\mathrm{C} 2$ & 1.52 & 1.50 & 1.51 \\
\hline $\mathrm{C} 1-\mathrm{C} 3$ & 1.49 & 1.48 & 1.49 \\
\hline $\mathrm{C} 1-\mathrm{N} 4$ & 1.44 & 1.43 & 1.44 \\
\hline $\mathrm{C} 1-\mathrm{H} 11$ & 1.09 & 1.08 & 1.08 \\
\hline $\mathrm{C} 2-\mathrm{C} 3$ & 1.51 & 1.50 & 1.51 \\
\hline $\mathrm{C} 2-\mathrm{C} 5$ & 1.48 & 1.49 & 1.48 \\
\hline $\mathrm{C} 2-\mathrm{H} 12$ & 1.08 & 1.08 & 1.08 \\
\hline $\mathrm{C} 3-\mathrm{H} 13$ & 1.08 & 1.08 & 1.08 \\
\hline $\mathrm{C} 3-\mathrm{H} 14$ & 1.08 & 1.09 & 1.08 \\
\hline
\end{tabular}

\begin{tabular}{|c|c|c|c|}
\hline N4-H15 & 1.01 & 1.02 & 1.01 \\
\hline N4-H16 & 1.01 & 1.02 & 1.01 \\
\hline C5-C6 & 1.40 & 1.41 & 1.40 \\
\hline C5-C10 & 1.40 & 1.41 & 1.40 \\
\hline C6-C7 & 1.39 & 1.40 & 1.39 \\
\hline C6-H17 & 1.08 & 1.09 & 1.08 \\
\hline C7-C8 & 1.39 & 1.38 & 1.39 \\
\hline C7-H18 & 1.08 & 1.07 & 1.08 \\
\hline C8-C9 & 1.39 & 1.40 & 1.39 \\
\hline C8-H19 & 1.08 & 1.09 & 1.08 \\
\hline C9-C10 & 1.39 & 1.40 & 1.39 \\
\hline C9-H20 & 1.08 & 1.08 & 1.08 \\
\hline
\end{tabular}




\begin{tabular}{|c|c|c|c|c|c|c|c|}
\hline C10-H21 & 1.08 & 1.08 & 1.08 & H15-N4-H16 & 106.9 & 106.8 & 106.8 \\
\hline \multicolumn{4}{|c|}{ Bond angle 0} & $\mathrm{C} 2-\mathrm{C} 5-\mathrm{C} 6$ & 119.3 & 119.2 & 119.3 \\
\hline $\mathrm{C} 2-\mathrm{C} 1-\mathrm{N} 4$ & 116.8 & 116.8 & 116.9 & $\mathrm{C} 2-\mathrm{C} 5-\mathrm{C} 10$ & 122.7 & 122.5 & 122.7 \\
\hline C2-C1-H11 & 114.6 & 114.8 & 114.8 & C6-C5-C10 & 117.9 & 117.8 & 1117.9 \\
\hline $\mathrm{C} 3-\mathrm{C} 1-\mathrm{N} 4$ & 117.1 & 117.1 & 117.1 & $\mathrm{C} 5-\mathrm{C} 6-\mathrm{C} 7$ & 121.2 & 121.3 & 121.2 \\
\hline C3-C1-H11 & 115.9 & 115.9 & 116.1 & C5-C6-H17 & 119.1 & 119.2 & 119.0 \\
\hline N4-C1-H11 & 118.7 & 118.4 & 118.3 & C7-C6-H17 & 119.6 & 119.5 & 119.6 \\
\hline $\mathrm{C} 1-\mathrm{C} 2-\mathrm{C} 5$ & 122.0 & 122.1 & 121.9 & C6-C7-C8 & 120.2 & 120.5 & 120.1 \\
\hline C1-C2-H12 & 113.3 & 113.3 & 113.2 & C6-C7-H18 & 119.6 & 119.5 & 119.6 \\
\hline $\mathrm{C} 3-\mathrm{C} 2-\mathrm{C} 5$ & 122.5 & 122.4 & 122.5 & С8-С7-H18 & 120.1 & 120.1 & 120.1 \\
\hline C3-C2-H12 & 114.3 & 114.5 & 114.3 & C7-C8-C9 & 119.2 & 119.2 & 119.2 \\
\hline C5-C2-H12 & 114.4 & 114.5 & 114.4 & C7-C8-H19 & 120.3 & 120.2 & 120.3 \\
\hline C1-C3-H13 & 116.9 & 116.8 & 117.0 & С9-С8-H19 & 120.3 & 120.3 & 120.3 \\
\hline C1-C3-H14 & 118.6 & 118.5 & 118.6 & C8-C9-C10 & 120.4 & 120.4 & 120.4 \\
\hline C2-C3-H13 & 116.7 & 116.5 & 116.8 & C8-C9-H20 & 120.0 & 120.0 & 120.0 \\
\hline C2-C3-H14 & 117.9 & 117.8 & 117.8 & C10-C9-H20 & 119.5 & 119.5 & 119.5 \\
\hline H13-C3-H14 & 115.1 & 115.2 & 115.1 & C5-C10-C9 & 120.9 & 120.9 & 120.9 \\
\hline C1-N4-H15 & 110.2 & 110.3 & 110.5 & C5-C10-H21 & 119.9 & 120.0 & 120.0 \\
\hline C1-N4-H16 & 110.3 & 110.5 & 110.6 & С9-С10-H21 & 119.0 & 118.9 & 118.9 \\
\hline
\end{tabular}

\section{Vibrational Assignments}

Table 2: Vibrational Assignments of 2PCP1A.

\begin{tabular}{|c|c|c|c|c|c|}
\hline \multicolumn{2}{|c|}{ Experimental frequency } & \multicolumn{3}{|c|}{ B3LYP } & \multirow{2}{*}{ Vibrational Band Assignments (PED\%) } \\
\hline FT-IR $\left(\mathrm{cm}^{-1}\right)$ & FT-R $\left(\mathrm{cm}^{-1}\right)$ & 6-31G(d,p) & $6-311++G(2 d, 3 p)$ & 6-31G(3df,3pd) & \\
\hline 3568 & 3566 & 3568 & 3565 & 3564 & $\mathrm{NH}_{2 \text { (asym) }}(100)$ \\
\hline 3488 & 3492 & 3484 & 3488 & 3492 & $\mathrm{NH}_{2(\text { sym })}(99)$ \\
\hline 3228 & 3234 & 3234 & 3228 & 3207 & $\mathrm{CH}_{2 \text { (asym) }}(92)$ \\
\hline 3185 & 3197 & 3204 & 3198 & 3185 & $\mathrm{CH}(11)$ \\
\hline 3192 & 3190 & 3192 & 3185 & 3172 & $\mathrm{CH}(92)$ \\
\hline 3172 & 3173 & 3185 & 3172 & 3163 & $\mathrm{CH}(95)$ \\
\hline 3152 & 3153 & 3175 & 3166 & 3152 & $\mathrm{CH}(49)$ \\
\hline 3149 & 3150 & 3172 & 3158 & 3149 & $\mathrm{CH}(92)$ \\
\hline 3146 & 3147 & 3169 & 3150 & 3146 & $\mathrm{CH}(99)$ \\
\hline 3129 & 3128 & 3143 & 3130 & 3120 & $\mathrm{CH}_{2(\mathrm{sym})}(94)$ \\
\hline 3064 & 3063 & 3068 & 3063 & 3061 & $\mathrm{CH}(10)$ \\
\hline 1662 & 1663 & 1664 & 1662 & 1660 & $\mathrm{CC}(18)+\mathrm{NH}_{2}(35)$ \\
\hline 1659 & 1660 & 1662 & 1658 & 1649 & $\mathrm{HCH}(38)+\mathrm{NH}_{2}(44)$ \\
\hline 1636 & 1637 & 1636 & 1625 & 1622 & $\mathrm{HCH}(62)$ \\
\hline 1532 & 1533 & 1544 & 1539 & 1532 & $\mathrm{HCH}(52)$ \\
\hline 1510 & 1510 & 1512 & 1501 & 1498 & $\mathrm{HCH}(91)$ \\
\hline 1473 & 1472 & 1486 & 1465 & 1473 & $\mathrm{HCH}(30)$ \\
\hline 1437 & 1437 & 1442 & 1437 & 1430 & $\mathrm{HCH}(48)$ \\
\hline 1372 & 1373 & 1374 & 1360 & 1365 & $\mathrm{HCH}(13)$ \\
\hline 1365 & 1366 & 1365 & 1352 & 1354 & $\mathrm{HCH}(64)$ \\
\hline 1330 & 1332 & 1331 & 1329 & 1322 & $\mathrm{HCH}(52)$ \\
\hline 1271 & 1270 & 1271 & 1270 & 1267 & $\mathrm{NH}_{2}(52)+\mathrm{HCH}(10)$ \\
\hline 1250 & 1250 & 1249 & 1248 & 1244 & $\mathrm{HCH}(68)$ \\
\hline
\end{tabular}


Juniper Online Journal Material Science

\begin{tabular}{|c|c|c|c|c|c|}
\hline 1222 & 1223 & 1226 & 1222 & 1219 & $\mathrm{HCH}(19)$ \\
\hline 1215 & 1214 & 1212 & 1210 & 1205 & $\mathrm{HCH}(34)$ \\
\hline 1178 & 1179 & 1186 & 1180 & 1178 & $\mathrm{HCH}(29)$ \\
\hline 1165 & 1168 & 1171 & 1167 & 1166 & $\mathrm{HCH}(23)$ \\
\hline 1122 & 1122 & 1125 & 1123 & 1119 & $\mathrm{HCH}(29)$ \\
\hline 1110 & 1111 & 1108 & 1110 & 1107 & $\mathrm{HCH}(46)$ \\
\hline 1095 & 1095 & 1092 & 1090 & 1087 & $\mathrm{HCH}(52)$ \\
\hline 1062 & 1063 & 1063 & 1060 & 1062 & $\mathrm{HCH}(22)$ \\
\hline 1056 & 1056 & 1058 & 1056 & 1053 & $\mathrm{HCH}(41)$ \\
\hline 1013 & 1012 & 1014 & 1013 & 1011 & $\mathrm{HCCH}(31)$ \\
\hline 995 & 994 & 998 & 995 & 996 & $\mathrm{HCNH}(21)$ \\
\hline 977 & 978 & 992 & 990 & 977 & $\mathrm{HCCH}(41)$ \\
\hline 965 & 964 & 966 & 965 & 972 & $\mathrm{HCCH}(28)$ \\
\hline 945 & 943 & 945 & 947 & 941 & $\mathrm{HCH}(52)$ \\
\hline 910 & 909 & 909 & 910 & 909 & $\mathrm{HCH}(37)$ \\
\hline 901 & 899 & 901 & 899 & 901 & $\mathrm{HCH}(52)$ \\
\hline 856 & 855 & 853 & 858 & 856 & $\mathrm{HCH}(52)$ \\
\hline 848 & 846 & 848 & 845 & 848 & $\mathrm{HCH}(52)+\mathrm{NH}_{2}(11)$ \\
\hline 814 & 813 & 814 & 813 & 814 & $\mathrm{HCH}(38)+\mathrm{NH}_{2}(14)$ \\
\hline 763 & 762 & 770 & 763 & 766 & $\mathrm{HCH}(72)$ \\
\hline 751 & 751 & 760 & 752 & 751 & $\mathrm{HCH}(33)+\mathrm{NH}_{2}(10)$ \\
\hline 639 & 640 & 641 & 648 & 637 & $\mathrm{HCH}(67)$ \\
\hline 635 & 634 & 634 & 635 & 631 & $\mathrm{HCCH}(31)$ \\
\hline 582 & 583 & 586 & 588 & 582 & $\mathrm{HCCH}(26)$ \\
\hline 515 & 514 & 538 & 520 & 515 & $\mathrm{HCH}(32)$ \\
\hline 439 & 440 & 441 & 448 & 439 & $\mathrm{HCH}(28)$ \\
\hline 402 & 402 & 417 & 402 & 399 & $\mathrm{HCH}(22)$ \\
\hline 375 & 375 & 377 & 375 & 375 & $\mathrm{HCH}(44)$ \\
\hline 340 & 341 & 339 & 340 & 336 & $\mathrm{HCH}(42)$ \\
\hline 298 & 297 & 312 & 308 & 298 & $\mathrm{HCH}(44)+\mathrm{NH}_{2}(10)$ \\
\hline 240 & 241 & 239 & 240 & 232 & $\mathrm{HCH}(34)+\mathrm{NH}_{2}(14)$ \\
\hline 162 & 162 & 162 & 159 & 162 & $\mathrm{HCH}(56)$ \\
\hline 106 & 108 & 107 & 106 & 106 & $\mathrm{HCH}(22)$ \\
\hline 48 & 49 & 49 & 48 & 47 & $\mathrm{HCH}(24)$ \\
\hline
\end{tabular}

The molecule 2PCP1A belongs to $\mathrm{C} 1$ point group symmetry, and its 57 fundamentals are distributed amongst the symmetry species as, all these modes are found to be active both in the Raman scattering and infrared absorption. The detailed vibrational assignment of fundamental modes of 2PCP1A along with the calculated IR and Raman frequencies and normal mode descriptions (characterized by PED) are reported in Table 2. For visual comparison, the observed and calculated FT-IR and FT-Raman spectra of 2PCP1A at DFT-B3LYP method using 6-31G(d,p), 6-311++G(2d,3p) and 6-31G(3df,3pd) basis sets are shown in Figures 1 (b) and 2(a) respectively. The main focus of the present investigation is the proper assignment of the experimental frequencies to the various vibrational modes of $2 \mathrm{PCP} 1 \mathrm{~A}$ in corroboration with the calculated harmonic vibrational frequencies at B3LYP level using the standard 6-31G(d,p),6-311++G(2d,3p) and 6-31G(3df,3pd) basis sets. Comparison of the frequencies calculated by DFT-B3LYP method with the experimental values reveals the overestimation of the calculated vibrational modes due to neglect of an harmonicity in real system.

\section{CH vibrations}

The aromatic structure shows the presence of $\mathrm{CH}$ stretching vibration in the region $3200-3000 \mathrm{~cm}^{1}$ which is the characteristic region for the identification of $\mathrm{CH}$ stretching vibration [13]. In this region, the bands are not affected appreciably by the nature of the constituents. For our title molecule the bands corresponding to $\mathrm{CH}$ stretching vibrations at 3204,3185 and 
$3172 \mathrm{~cm}^{1}$ by DFT methods show excellent agreement with the literature data and also with the band observed in the recorded FT-IR spectrum at $3172 \mathrm{~cm}^{1}[14,15]$. The PED corresponding to this vibration is pure mode of contributing more than $90 \%$ as shown in Table 2. Ring Vibrations. Many ring modes are affected by the substitutions in the ring of midodrine. The actual position of these modes are determined not so much by the natural of the substituents but by the form of substitution around the ring system [16]. In our present study the wave number computed 1663,1662 and $1660 \mathrm{~cm}^{1}$ by B3LYP methods are assigned to CC stretching vibrations for the title molecule shows good agreement with recorded spectra. The in-plane and out-of-plane bending vibration are computed by DFT/6-31G(d,p), 6-311++G(2d,3p) and $6-31 \mathrm{G}(3 \mathrm{df}, 3 \mathrm{pd})$ methods show good agreement with literature $[18,19]$ and recorded spectral data.
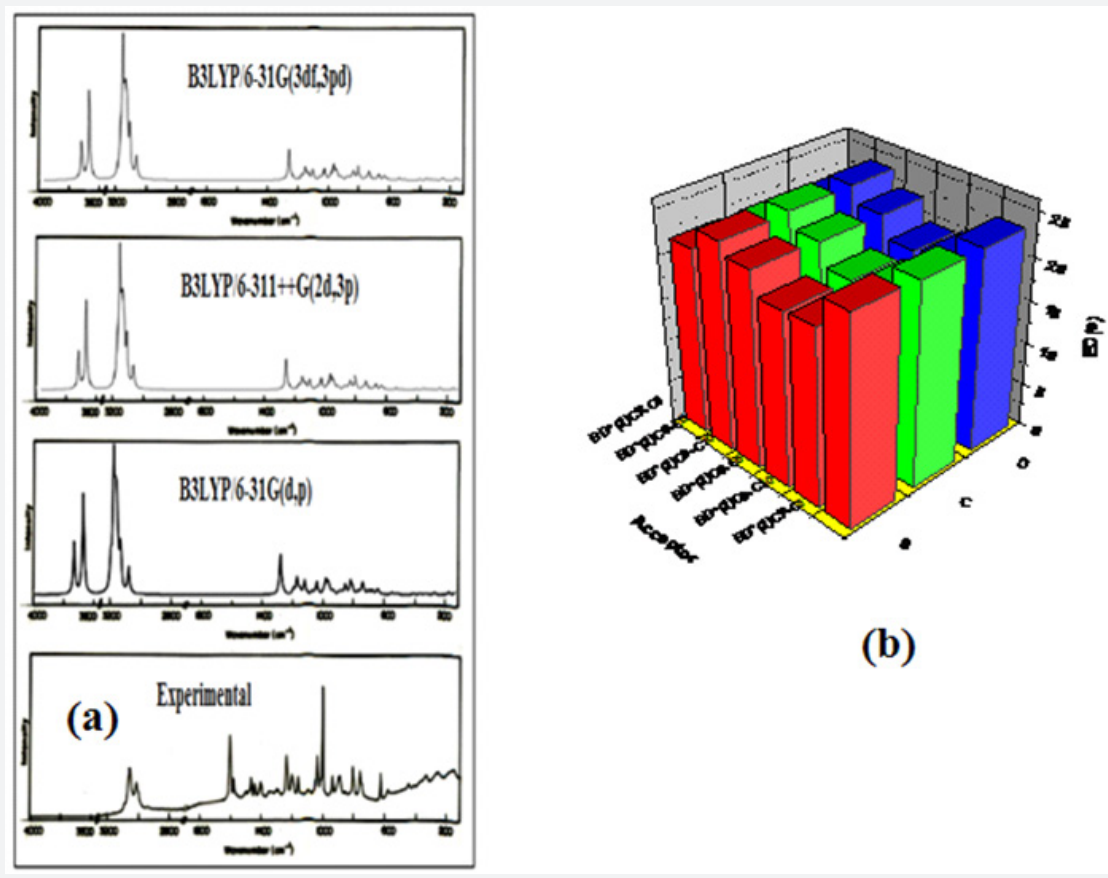

(b)

Figure 2: a) FT-Raman spectra of 2PCP1A and b) NBO analysis of 2PCP1A.

\section{$\mathrm{NH}_{2}$ Vibrations}

Primary aliphatic amides absorb in the region $3520-3320 \mathrm{~cm}$ ${ }^{1}$ [17]. The position of absorption in this region depends upon the degree of hydrogen bonding and the physical state of the sample or the polarity of the solvent. The $\mathrm{NH}_{2}$ asymmetric and symmetric stretching modes are $3568,3564 \mathrm{~cm}^{-1}$ and $3488,3484 \mathrm{~cm}^{-1}$ by B3LYP basis sets, while the experimental values are 3568 and $3566 \mathrm{~cm}^{-1}$ in FT-IR and FT-Raman spectrum respectively. They are presented in Table 2. The PED contributions are 100\% for stretching mode.

\section{NBO Analysis}

Natural bond analysis gives the accurate possible natural Lewis structure picture of because all orbitals are mathematically chosen to include the highest possible percentage of the electron density. Interaction between both filled and virtual orbital spaces information correctly explained by the NBO analysis could enhance the analysis of intra- and intermolecular interactions. The second order Fock matrix was carried out to evaluate donor (i) and acceptor (j) i.e. donor level bonds to acceptor level bonds interaction in the NBO analysis [18]. The result of interaction is a loss of occupancy from the concentrations of electron NBO of the idealized Lewis structure into an empty non-Lewis orbital. For each donor(i) and acceptor(j), the stabilization energy E(2) associated with the delocalization ij is estimated a where qi is the donor orbital occupancy, $\varepsilon$ i and $\varepsilon$ j are diagonal elements and $F(i, j)$ is the off diagonal NBO Fock matrix element.

Natural bond orbital analysis is used for investigating charge transfer or conjugative interaction in the molecular systems. Some electron donor orbital, acceptor orbital and the interacting stabilization energy results from the second-order microdisturbance theory are reported $[19,20]$. The larger E(2) value the more intensive is the interaction between electron donors and acceptors, i.e. the more donation tendency from electron donors to electron acceptors and the greater the extent of conjugation of the whole system [21]. Delocalization of electron density between occupied Lewis-type (bond or lone pair) NBO orbitals and formally unoccupied (antibond or Rydgberg) non-Lewis NBO orbitals correspond to a stabilization donoracceptor interaction. NBO analysis has been performed on the 2PCP1A molecule at the DFT levels in order to elucidate the intramolecular interaction within the molecule. 
The intramolecular interaction is formed by the orbital overlap between bonding $\mathrm{BD}(2) \mathrm{C} 5 \mathrm{C} 6, \mathrm{BD}(2) \mathrm{C} 9-\mathrm{C} 10$ and antibonding $\mathrm{BD}^{*}(2) \mathrm{C} 7-\mathrm{C} 8, \mathrm{BD} *(2) \mathrm{C} 5-\mathrm{C} 6$ orbital, which results in the intramolecular charge transfer causing stabilization of the system. The second-order perturbation theory of Fock matrix in the NBO analysis shows strong intramolecular hyperconjugative interactions and the results are shown in Table 3. The most important interactions observed are BD(2)C9C10BD*(2)C5-C6 and $\mathrm{BD}(2) \mathrm{C} 5-\mathrm{C} 6 \mathrm{BD}^{*}(2) \mathrm{C} 7-\mathrm{C} 8$ and the corresponding energies are 24.30 and $23.78 \mathrm{~kJ} / \mathrm{mol}$ respectively. This larger energy provides the stabilization to the molecular structure. Graphical representation NBO analysis is shown in Figure 2(b).

Table 3: Second order perturbation theory analysis of Fock matrix in NBO analysis and UV-Vis excitation energy (E) of 2PCP1A.

\begin{tabular}{|c|c|c|c|c|c|c|}
\hline \multirow{2}{*}{ Donor(i) } & \multirow{2}{*}{\multicolumn{2}{|c|}{ Acceptor (j) }} & \multicolumn{4}{|c|}{ Calculated E $(2) \mathrm{a}(\mathrm{kJ} / \mathrm{mol})$} \\
\hline & & & \multicolumn{2}{|c|}{$6-31 G(d, p)$} & $6-311++G(2 d, 3 p)$ & 6-31G(3df,3pd) \\
\hline \multirow[t]{2}{*}{$\mathrm{BD}(2) \mathrm{C} 5-\mathrm{C} 6$} & \multicolumn{2}{|c|}{$\mathrm{BD}^{*}(2) \mathrm{C} 7-\mathrm{C} 8$} & \multicolumn{2}{|c|}{23.78} & 23.46 & 23.47 \\
\hline & \multicolumn{2}{|c|}{$\mathrm{BD}^{*}(2) \mathrm{C} 9-\mathrm{C} 10$} & \multicolumn{2}{|c|}{20.39} & 20.38 & 20.34 \\
\hline \multirow[t]{2}{*}{$\mathrm{BD}(2) \mathrm{C} 7-\mathrm{C} 8$} & \multicolumn{2}{|c|}{$\mathrm{BD}^{*}(2) \mathrm{C} 5-\mathrm{C} 6$} & \multicolumn{2}{|c|}{20.17} & 19.98 & 19.96 \\
\hline & \multicolumn{2}{|c|}{$\mathrm{BD}^{*}(2) \mathrm{C} 9-\mathrm{C} 10$} & \multicolumn{2}{|c|}{22.77} & 22.50 & 22.45 \\
\hline \multirow[t]{2}{*}{$\mathrm{BD}(2) \mathrm{C} 9-\mathrm{C} 10$} & \multicolumn{2}{|c|}{$\mathrm{BD} *(2) \mathrm{C} 5-\mathrm{C} 6$} & \multicolumn{2}{|c|}{24.10} & 24.30 & 24.29 \\
\hline & \multicolumn{2}{|c|}{$\mathrm{BD}^{*}(2) \mathrm{C} 7-\mathrm{C} 8$} & \multicolumn{2}{|c|}{21.63} & 21.65 & 21.54 \\
\hline \multicolumn{7}{|c|}{ a E(2) means energy of hyper conjugative interaction (stabilization energy) } \\
\hline \multirow{3}{*}{ States } & \multicolumn{4}{|c|}{ TD-B3LYP/6-31G(d,p) } & \multirow{3}{*}{ Expt. } & \multirow{3}{*}{ Major Contributions } \\
\hline & \multicolumn{2}{|c|}{ Gas phase } & \multicolumn{2}{|c|}{ Water } & & \\
\hline & cal & $\mathrm{E}(\mathrm{eV})$ & cal & $\mathrm{E}(\mathrm{eV})$ & & \\
\hline S1 & 227.27 & 5.4553 & 230.61 & 5.3764 & 225 & HOMO->LUMO (94\%) \\
\hline S2 & 219.09 & 5.6589 & 222.11 & 5.5820 & 220 & HOMO->L+1 (92\%) \\
\hline S3 & 213.88 & 5.7968 & 214.22 & 5.7876 & 210 & $\begin{array}{c}\mathrm{H}-2->\operatorname{LUMO}(-16 \%) \\
\mathrm{H}-2->\mathrm{L}+1(-19 \%)\end{array}$ \\
\hline
\end{tabular}

\section{Molecular Electrostatic Potential (MEP)}

The MEP is a useful feature to study reactivity given that an approaching electrophile will be attracted to negative regions (where the electron distribution effect is dominant). The importance of MEP lies in the fact that it simultaneously displays molecular size, shape as well as positive, negative and neutral electrostatic potential regions in terms of color grading and is very useful in research of molecular structure with its physicochemical property relationship [22,23]. The resulting surface simultaneously displays molecular size, shape and electrostatic potential value. In the majority of the MEP, while the maximum negative region which preferred site for electrophilic attack indications as red color, the maximum positive region which preferred site for nucleophilic attack symptoms as blue color. The different values of the electrostatic potential at the surface are represented by different colors. Potential increases in the order red $<$ orange $<$ yellow $<$ green $<$ blue.

In this study, the color code of the map is in the range between -0.01054 a.u. (deepest red) and 0.01054a.u. (deepest blue) in the studied compound, where blue indicates the strongest attraction and red indicates the strongest repulsion. The MEPs of 2PCP1A molecule in 3D plots are represented in Figure 3(a). As can be seen from the MEP map shown in figure, although the regions having the negative potential are over the carbon and nitrogen (the electronegative atoms) and also the regions having the positive potential are over hydrogen atoms localized a maximum positive region. From these results, we can say that the ring, the nitrogen atom and all hydrogen atoms (especially H16 atom) indicate the strongest attraction and C3 and N4 atoms indicate the strongest repulsion.

\section{Molecular Orbitals Transport Properties}

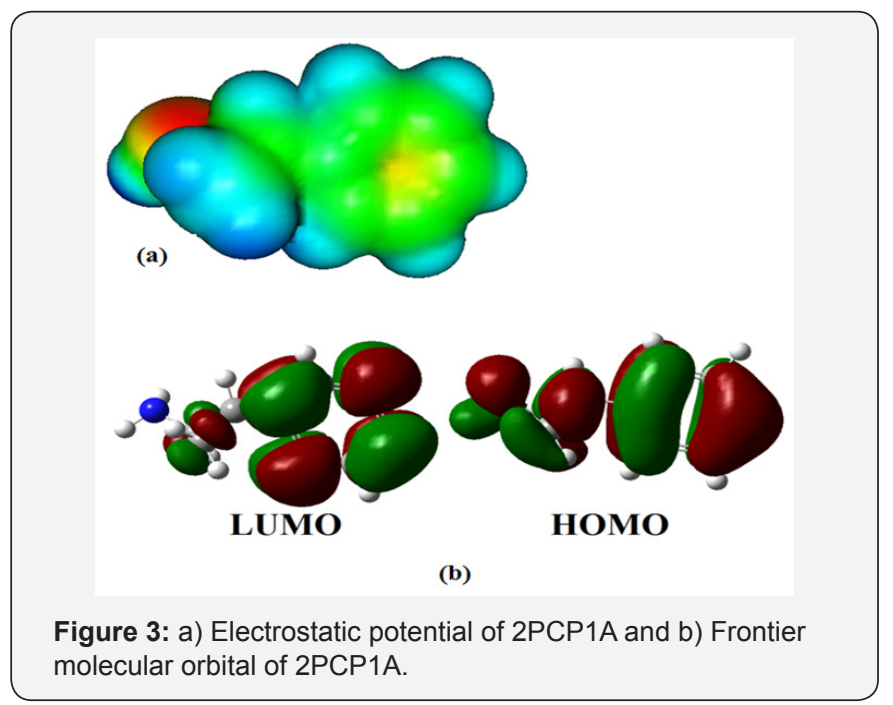

The HOMO-LUMO gap results in a significant degree of electric excitation and charge transfer. In most cases, even in the absence of inversion symmetry, the strongest band in the Raman spectrum is weak in the IR spectrum and vice versa. Changes in the HOMO-LUMO gap by connecting with some noble metal or semiconductor or some other means result in the change of the charge transfer degree, intensity and position of the peak. 
The HOMO-LUMO gap estimated to be $6.04 \mathrm{eV}$ at the B3LYP/6$31 \mathrm{G}(\mathrm{d}, \mathrm{p})$ level and the frontier orbitals are illustrated in Figure 3(b).The experimental and theoretical UV-Vis spectra are shown in Figure 4(a). Theoretical and experimental maximum absorption wavelengths and excitation energy are collected in Table 3. The observed peaks were found at $225 \mathrm{~nm}$ in the water phase. The calculated peaks were found at $227 \mathrm{~nm}$ in the gas phase. The calculated peaks were thus $2 \mathrm{~nm}$ higher than the observed peaks, and this error may have been caused by the error of PCM modeling.

\section{Natural Population Analysis}

The calculation of atomic charges plays an important role in the application of quantum mechanical calculations to molecular systems [24]. Our interest here is in the comparison of different methods to describe the electron distribution in 2PCP1A as broadly as possible, and assess the sensitivity of the calculated charges to changes in (i) the choice of the basis set and (ii) the choice of the quantum mechanical method. Mulliken charges, calculated by determining the electron population of each atom as defined in the basis functions. The Mulliken charges calculated at different levels basis sets are listed in Table 4. The corresponding Mulliken's plot with B3LYP different basis sets are shown in Figure 4(b).

Table 4: Mulliken atomic charges and Molecular properties of 2PCP1A.

\begin{tabular}{|c|c|c|c|}
\hline \multirow{2}{*}{ Atoms } & \multicolumn{3}{|c|}{ B3LYP } \\
\cline { 2 - 4 } & $\mathbf{6 - 3 1 G ( d , p )}$ & $\begin{array}{c}\mathbf{6 - 3 1 + + G} \\
\mathbf{( 2 d , 3 p )}\end{array}$ & $\begin{array}{c}\mathbf{6 - 3 1 G} \\
\mathbf{( 3 d f , 3 p d )}\end{array}$ \\
\hline C1 & 0.026589 & 0.030345 & 0.128448 \\
\hline C2 & -0.015955 & -0.160519 & 0.303033 \\
\hline C3 & -0.212656 & -0.213333 & -0.347465 \\
\hline N4 & -0.597307 & -0.605409 & -0.540817 \\
\hline C5 & 0.194118 & 0.195278 & 0.087696 \\
\hline C6 & -0.140398 & -0.140516 & -0.074285 \\
\hline
\end{tabular}

\begin{tabular}{|c|c|c|c|}
\hline C7 & -0.084941 & -0.084638 & -0.153163 \\
\hline C8 & -0.089668 & -0.089638 & -0.278256 \\
\hline C9 & -0.086862 & -0.086972 & -0.089999 \\
\hline C10 & -0.149335 & -0.150573 & -0.230494 \\
\hline H11 & 0.082292 & 0.094466 & 0.069303 \\
\hline H12 & 0.106929 & 0.096682 & 0.081655 \\
\hline $\mathrm{H} 13$ & 0.126486 & 0.117570 & 0.090952 \\
\hline H14 & 0.113109 & 0.116024 & 0.088046 \\
\hline H15 & 0.239854 & 0.244086 & 0.163166 \\
\hline H16 & 0.236448 & 0.239490 & 0.158355 \\
\hline H17 & 0.079777 & 0.067663 & 0.101850 \\
\hline H18 & 0.082257 & 0.073013 & 0.111664 \\
\hline H19 & 0.078718 & 0.082042 & 0.107057 \\
\hline $\mathrm{H} 20$ & 0.079439 & 0.091732 & 0.106178 \\
\hline $\mathrm{H} 21$ & 0.074704 & 0.083206 & 0.117076 \\
\hline \multirow[b]{2}{*}{$\begin{array}{l}\text { Molecular } \\
\text { Properties }\end{array}$} & \multicolumn{3}{|c|}{ B3LYP } \\
\hline & $6-31 G(d, p)$ & $\begin{array}{l}6-311++ \\
G(2 d, 3 p)\end{array}$ & $\begin{array}{c}\text { 6-31G } \\
\text { (3df,3pd) }\end{array}$ \\
\hline $\mathrm{HOMO}(\mathrm{eV})$ & -5.9715 & -6.2888 & -6.0877 \\
\hline LUMO $(\mathrm{eV})$ & 0.0938 & -0.3613 & -0.0389 \\
\hline$(\mathrm{H}-\mathrm{L})(\mathrm{eV})$ & 6.0653 & 5.9275 & 6.0488 \\
\hline $\begin{array}{c}\text { Ionization } \\
\text { potential(I) }\end{array}$ & 5.9715 & 6.2888 & 6.0877 \\
\hline $\begin{array}{c}\text { Electron } \\
\text { affinity(A) }\end{array}$ & 0.0938 & 0.3613 & 0.0389 \\
\hline $\begin{array}{c}\text { Chemical } \\
\text { hardness() }\end{array}$ & 2.9388 & 2.9637 & 3.0244 \\
\hline $\begin{array}{c}\text { Chemical } \\
\text { potential0 }\end{array}$ & -3.0326 & -3.3250 & -3.0633 \\
\hline Electronegativity() & 3.0326 & 3.3250 & 3.0633 \\
\hline $\begin{array}{l}\text { Electrophilicity } \\
\text { index() }\end{array}$ & 4.5983 & 5.5278 & 4.6919 \\
\hline Softness(S) & 0.3402 & 0.3374 & 0.3306 \\
\hline
\end{tabular}

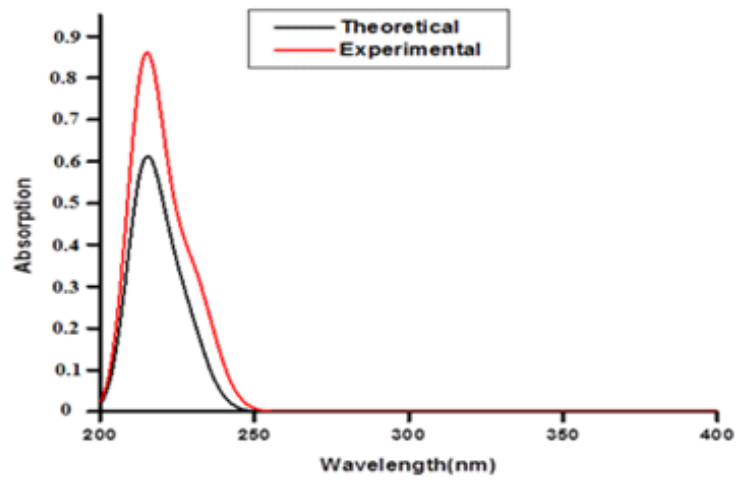

(a)

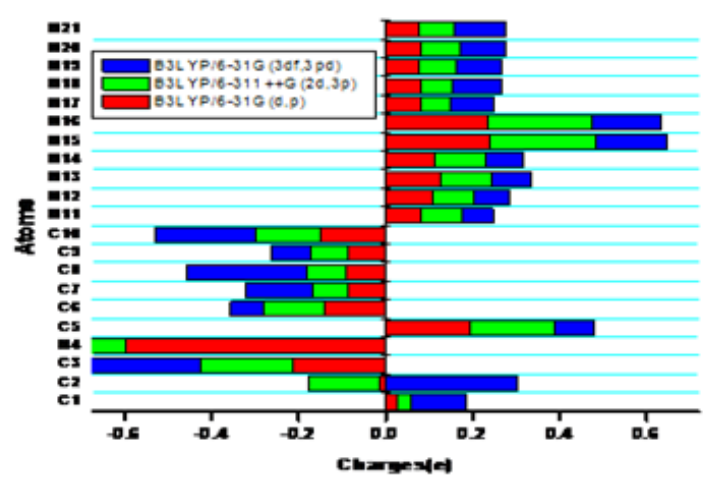

(b)

Figure 4: a) UV-Visible spectrum of 2PCP1A and b) Natural population analysis of 2PCP1A. 


\section{Global Reactivity and Charge Reactivity Descriptors}

The other electronic properties as the chemical potential (), electronegativity (), electrophilicity index 0 and chemical hardness () are given in Table 4. The, and are important tools to study the order of stability of molecular systems. Using HOMO and LUMO energies, the and have been calculated. The chemical hardness and the chemicalpotential are given by the following expression,(IA)/2, (IA)/2. The, which measures the stabilization energy, has been given by the following expression, in terms of electronic chemical potential and the chemical hardness: $2 / 2$ electro negativity (),(IA)/2or where I and A are ionization potential and electron affinity of a molecular system [25-28].

\section{Thermodynamics Properties}

On the basis of vibrational analysis at B3LYP/6-31G(d,p), 6-311++G(2d,3p) and 6-31G(3df,3pd)levels and several thermodynamic parameters are calculated and are compared in Table 5. The zero point vibration energies (ZPVE) and the entropy, $S_{\text {vib }}(T)$ are calculated with B3LYP methods are to the extent of accuracy and the variations in ZPVEs seem to be insignificant. The dipole moment calculated using B3LYP/6$31 \mathrm{G}(\mathrm{d}, \mathrm{p}), 6-311++\mathrm{G}(2 \mathrm{~d}, 3 \mathrm{p})$ and 6-31G(3df,3pd) basis sets are found. The total energies and the change in the total entropy of2PCP1A at room temperature are found to be marginal.

Table 5: Thermodynamic functions of 2PCP1A.

\begin{tabular}{|c|c|c|c|}
\hline \multirow{2}{*}{ Parameters } & \multicolumn{3}{|c|}{ B3LYP } \\
\hline & 6-31G(d,p) & $6-311++G(2 d, 3 p)$ & 6-31G(3df,3pd) \\
\hline $\mathrm{ZPVE}(\mathrm{KJ} / \mathrm{mol})$ & 113.05 & 112.30 & 112.29 \\
\hline Rotational constant $\mathrm{x}$ & 3.531 & 3.533 & 3.542 \\
\hline $\mathrm{y}$ & 0.743 & 0.742 & 0.745 \\
\hline $\mathrm{Z}$ & 0.679 & 0.680 & 0.681 \\
\hline Thermal Energy (kJ/mol) & 0.188 & 0.188 & 0.187 \\
\hline \multicolumn{4}{|c|}{ Entropy (cal/mol -1K-1) } \\
\hline Total & 92.17 & 92.51 & 92.69 \\
\hline Translational & 40.57 & 40.58 & 40.57 \\
\hline Rotational & 29.57 & 29.52 & 29.56 \\
\hline Vibrational & 22.02 & 22.03 & 22.54 \\
\hline \multicolumn{4}{|c|}{ Dipole moment (Debye) } \\
\hline$\mu \mathrm{x}$ & -0.6341 & 0.1800 & -0.5402 \\
\hline$\mu \mathrm{y}$ & -0.1856 & -0.6571 & -0.6539 \\
\hline$\mu \mathrm{z}$ & -1.0036 & -0.8871 & -0.5228 \\
\hline Total & 1.6778 & 1.1186 & 0.9963 \\
\hline \multicolumn{4}{|c|}{ Heat capacity(CV) } \\
\hline Total & 34.68 & 35.10 & 35.09 \\
\hline Translational & 2.981 & 2.981 & 2.981 \\
\hline Rotational & 2.981 & 2.981 & 2.981 \\
\hline Vibrational & 28.72 & 29.15 & 29.13 \\
\hline \multicolumn{4}{|c|}{ Enthalphy(E) } \\
\hline Total & 118.55 & 117.87 & 117.86 \\
\hline Translatioanal & 0.889 & 0.889 & 0.889 \\
\hline Rotational & 0.889 & 0.889 & 0.889 \\
\hline Vibrational & 116.77 & 116.10 & 116.09 \\
\hline
\end{tabular}

\section{Conclusion}

A complete vibrational analysis of 2PCP1A was performed by B3LYP/6-31G(d,p), 6-311++G(2d,3p) and 6-31G(3df,3pd) basis sets. This study demonstrates that the DFT (B3LYP) calculations are powerful approach for understanding the vibrational spectra of the title molecule. FT-IR, FT-Raman and UV-spectral studies of 2PCP1A were carried out. The molecular structure analysis has been performed based on the quantum mechanical approach by DFT calculation. The vibrational modes are assigned on the basis of PED percentage. NBO analysis indicates the strong intramolecular hyperconjugative interaction within the molecule and stability of the molecule. Mulliken charges on 2PCP1A at different levels were calculated and the results discussed. HOMO, LUMO energies and HOMO-LUMO energy gap was also calculated. The maximum absorption peak max $_{\text {in }}$ in the UV-Vis spectrum has been observed at $304 \mathrm{~nm}$. The MEP map shows that the negative 
potential sites are on nitrogen and some of the carbon atoms as well as the positive potential sites are on the hydrogen and carbon atoms in the molecule.

\section{References}

1. Sustmann R and Sicking W (1996) Influence of Reactant Polarity on the Course of $(4+2)$ Cycloadditions. J Am Chem Soc 118(50): 1256212571.

2. Domingo LR and JAurell M (2002) Palladium-Catalyzed Aminoallylation of Activated Olefins with Allylic Halides and Phthalimide. J Org Chem 67(17): 5977-5980.

3. Godbout JT, Zuilhof H, Heim G, Gould IR, Goodman JL, et al. (2000) J Ram Spec 31(4): 233-241.

4. Kryspin H, Haufe G, Grimme S (2004) Chemistry 14: 3411-3422.

5. Matthew F, Tamara M, and Marc M (2014) J Am Chem Soc 12: 30-41.

6. Hohenberg P and Kohn P (1964) Phys Rev B 136: 864-871.

7. Becke AD (1993) J Chem. Phys 98: 5648-5652.

8. Becke AD (1988) Phys. Rev A 38: 3098-3100.

9. Lee C, Yang W, Parr RG (1988) Phys. Rev. B 37: 785-789.

10. Frisch MJ, Trucks GW, Schlegel HB (2003) Gaussian, Inc., Wallingford CT, Schlegel HB (1982) J Comput Chem 3: 214-218.

11. Jamroz MH (2004) Vibrational Energy Distribution Analysis VEDA 4. Spectrochim Acta A Mol Biomol Spectrosc. Poland.

12. Pagan none M, Formari B, and Mattel G (1986) Spectrochim Acta 43A: 621-625.

This work is licensed under Creative Commons Attribution 4.0 Licens DOI: 10.19080/JOJMS.2017.03.555604
13. Ozel AE, Celik S, and Akyuz S (2009) J Mol Struct 924: 523-530.

14. Krishnakumar V, Dheivamalar S (2008) Spectrochim. Acta 71A: 465470.

15. Bellamy LJ (1959) The Infrared Spectra of Complex Molecules. Wiley, New York, USA.

16. Reed AE, ACurtiss L, Weinhold F (1988) Chem Rev 88: 899-926.

17. Szafran M, Komasa A, Adamska EB(2007) J. Mol. Struct.(THEOCHEM) 827: 101-118.

18. James C, Amal Raj A, Rehunathan R, Hubert Joe I, Jayakumar VS, et al. (2006) J. Raman Spectrosc. 37: 1381.

19. Liu Jun-na, Chen Zhi-rang, Yuan Shen-fang, Zhejiag J (2005) University Sci. 6B, 584 .

20. Sebastian S, Sundaraganesan N (2010) Spectrochim. Acta 75A, 941.

21. Murray JS, Sen K (1996) Molecular Electrostatic Potentials, Concepts and Applications. 3(1).

22. Scrocco E, Tomasi J (1978) Advances in Quantum Chemistry, Academic Press, New York.

23. Gunasekaran S, Kumaresan S, Arunbalaji R, Anand G, Srinivasan S,et al. (2008) J Chem Sci 120: 315.

24. Parr RG, Szentpaly L, Liu S (1999) J Am Chem Soc 121: 1922-1924.

25. Chattaraj PK, Maiti B, Sarkar U (2003) J Phys Chem A 107: 4973-4975.

26. Parr RG, Donnelly RA, Levy M, Palke WE (1978) J Chem Phys 68: 38013807.

27. Parr RG, Pearson RG (1983) J Am Chem Soc 105: 7512-7516.

28. Parr RG, Chattraj PK (1991) J Am Chem Soc 113: 1854-1855.

\section{Your next submission with Juniper Publishers} will reach you the below assets

- Quality Editorial service

- Swift Peer Review

- Reprints availability

- E-prints Service

- Manuscript Podcast for convenient understanding

- Global attainment for your research

- Manuscript accessibility in different formats

( Pdf, E-pub, Full Text, Audio)

- Unceasing customer service

Track the below URL for one-step submission https://juniperpublishers.com/online-submission.php 